well arranged and pleasant to read. The subjects covered actually exceed the scope of the title in including imported agricultural crops which are processed in Britain, such as oil-bearing seeds, and also industrial biological products, such as malt, alcohol and antibiotics. Foodstuffs certainly predominate among the materials investigated, but attention is also given to non-edible products such as timber, leather, wool, cotton, paper and glue.

Agricultural crops. In Britain farmers grow only about one-third of the nation's wheat requirements, and nearly all the maize is imported. Almost all the barley and oats, however, are home grown. About half the barley is made into malt, and is used mainly for brewing and distilling; most of the rest is given to farm animals, which also receive nearly 80 per cent of the oats. The small quantity of home-grown rye is used for human consumption. The economical use of straw has attracted attention, and by predigestion with alkali its digestibility by animals has been increased. In the sugar beet industry the residual pulp left after the removal of the sugar has proved valuable as fodder, but an economical use for the foliage has still to be found. Pomace, left after pressing apples for making eider, is used both as fodder and as a source of pectin for the jam industry. Interesting regional differences are seen in the production of different vegetable crops in various parts of the country. Thus Ulster specializes in potatoes, Lincolnshire in peas and beans, and East Anglia in sugar beet. Peat is classified, perhaps rather strangely, as an agricultural crop ; it contains about 12 per cent of wax which might be used for the manufacture of polishes and in electric cables. The imported crops which are processed in Britain include oil-bearing seeds, coffee, tea, cocoa, cotton, jute, hemp and tobacco.

Animal products. Milk is such an excellent food that it is wasteful, except when the production exceeds the demand, to use it other than in liquid form. It is satisfactory, therefore, that only 10 per cent of the output in Britain is used for making butter, cheese, dried milk and other products. In the meat industry little seems to be wasted, except quantities of blood which exceed the capacity of the processing plants. Whole dried blood is used as a fertilizer, and the separated albumin in making plywood and paint. Collections of organs and glands for the extraction of hormones and other medical products are now made on 85 per cent of the animals killed in government slaughter-houses. A valuable source of leather is lost because few pigs are flayed, because bacon and pork are best marketed with the skin intact. Wool fat is a rich source of various waxy alcohols and also of cholesterol, which is a valuable starting material for the synthesis of certain hormones and vitamin $\mathrm{D}_{3}$. In the Bradford area no less than 8,500 tons of wool wax are recovered annually from the sewage; most of the wax is used on the railways as axle grease.

Biological products. The brewing industry, with all its ramifications, is based essentially on the culture of micro-organisms. It is estimated that 130,000 tons of carbon dioxide are given off annually in the course of brewing. The gas has several important industrial applications, but the supply far exceeds the demand. A more modern application of microbiology has been the production of antibiotics such as penicillin and streptomycin. The 'felt' formed by the micro-organisms is a rich source of vitamins of the B group. Starch is produced in Britain to the extent of 46,000 tons from maize, with only 2,100 tons from rice and 3,850 tons from wheat.

Timber. In Britain there is only 0.07 of an acre of forest per person as compared with $6 \cdot 47$ acres in Norway and 0.85 acre in Europe as a whole. The constant need to import timber, and the chronic scarcity of supplies, are therefore readily understandable. Steps are being taken to rebuild the stock of standing timber after the inroads made necessary by the Second World War. Although one cannot hope to satisfy current requirements, reserves may at least be accumulated against a future emergency. Most of the timber is located in Scotland. Attention is also being given to the efficient use of wood waste. Small pieces of wood and sawdust may be used to make hard-board, paper or briquettes for fire lighting. Vanillin may be manufactured from the sulphite liquor obtained in the manufacture of paper from wood. The liquor may also be fermented to give alcohol, yeast or other products.

Research and development. The report includes a useful list of the research institutions concerned in the production or efficient utilization of the materials which come within its scope. The absence or sparsity of the analytical data on many important products is stressed, and the collection of more adequate information is strongly urged. Another pressing need is the provision of more adequate facilities for investigating processes for industrial application on the 'pilot plant' scale. Only a few laboratories have any plant at all, and it is usually old-fashioned or even unserviceable. Practically no chemical engineers, moreover, are employed by the Department of Scientific and Industrial Research, and none by the Ministry of Agriculture and Fisheries or by the Agricultural Research Council.

The authors are to be congratulated for enabling research workers employed by these organizations, and others, to learn more of what is going on outside their own orbits of activity. The prosperity of Great Britain may largely depend on how far this widening and quickening of interest can be sustained and extended. THOMAS MOORE.

\section{RESEARCH AND DEVELOPMENT AT NON-PROFIT INSTITUTIONS IN THE UNITED STATES*}

A STUDY of the funds administered by United A States Federal agencies for research and development at non-profit institutions during 195051 and 1951-52, which has recently been completed by the National Science Foundation, indicates the extent to which the Federal Government now sponsors research and development at such institutions, rather than conducting the work in its own laboratories. While in 1940 sponsored research and development accounted for less than 10 per cent of all government expenditure for this purpose, in 1952 it accounted for 75 per cent. According to the study, Federal agencies administered $\mathbf{3 3 8}$ million dollars for scientific research and development at non-profit institutions during 1951-52, compared with 294 million dollars

* The National Science Foundation. Federal Funds for Science. 1 ; Federal Funds for Scientiflc Researeh and Development at Non-profit Institutions $1950-1951$ and $1951-1952 .{ }_{0}$ Pp. vi +48 . 
during 1950 51. Such institutions received 16 per cent of all Federal research and development funds during 1950-51, but only 15 per cent during 1951-52. The distribution among administering agencies and receiving institutions, and the nature of the work sponsored, showed little variation between the two years.

During 1951-52, seventeen agencies of the U.S. Government sponsored research and development at non-profit institutions; but four agencies administered 98 per cent of the funds. The Department of Defense administered 53 per cent, the Atomic Energy Commission 36 per cent, the Federal Security Agency 5 per cent, and the Department of Agriculture 4 per cent. In the Department of Defense, the Department of the Navy accounted for 36 per cent of the total, or 64 million dollars, compared with the 62 million dollars of the Department of the Air Force and 51 million dollars of the Department of the Army.

Of the 427 recipient institutions, 403 were located in the United States, Alaska, Hawaii and Puerto Rico, and 295 million dollars went to 225.educational institutions, while three special research organizations, namely, the Brookhaven National Laboratory and the Oak Ridge Institute of Nuclear Studies, both of which are sponsored by the Atomic Energy Commission and operated under the joint auspices of groups of universities, and the Rand Corporation, which is operated by an independent organization, are closely related to educational institutions. The independent research organizations, forty-eight of which receive Federal grants, are, with the exception of the special research centres formed at the request of the Government, the sole institutional group with the primary purpose of conducting scientific research and development. Almost half these organizations, which received 17 million dollars during 1951-52, have been established within the past twenty years, and during the two years for which data are available the number of such organizations participating in Federal sponsored research and development increased from forty-three to forty-eight. During 1951-52, twenty-four research centres, defined as research and development projects, administered by non-profit institutions for the Federal Government, received funds; and all but three were operated by educational institutions, 47 per cent of the funds that went to non-profit institutions (or 159 million dollars) being received by these centres mainly for defence work or work related to defence.

Funds for programmes devoted primarily to scientific research and development amounted to 58 million dollars, and the total funds for support of research and development are estimated at about 75 million dollars, or rather more than 20 per cent of the total. During 1951-52 applied research received $5 \cdot 1$ per cent of the funds, development activity $22 \cdot 9$ per cent, and basic research 21 per cent. Most of the funds were assigned for work in the physical sciences, biological sciences during 1951-52 receiving 19 per cent, social sciences 3 per cent, increase of research and development plant 6 per cent, and the remainder going to the physical sciences. Of the recipient institutions, 39 per cent were universities, 18 per cent being professional technical schools and the remainder liberal arts colleges. Federal grants for the support of agricultural experimental stations were about 12 million dollars, and accounted for about a quarter of the funds available to the stations.

\section{ISOTOPIC SPIN SELECTION RULES}

\author{
By DR. D. H. WILKINSON \\ Cavendish Laboratory, Cambridge
}

\section{Isotopic Spin}

$T$ has long been recognized that, in some sense or 1 other, the neutron and proton may be regarded as alternative states of the same particle, distinguished, without any specific assumption about nuclear forces, by the value of the isotopic spin co-ordinate ${ }^{1}$. The isotopic spin of the individual nucleon, the projection of which on the $z$-axis is represented by the value of the isotopic spin co-ordinate, bears a strong formal resemblance to ordinary intrinsic spin; the isotopic spin operators are closely related to the Pauli spin matrices. The idea of alternative nucleon states is suggested by the near-identity of the masses of neutron and proton, by their mutual interconversions that take place in ordinary beta-decay, by the betadecay of the free neutron ${ }^{2}$ and by the supposed role of charged mesons in connexion with nuclear forces; more recently we may add the transmutation of one nucleon into the other in reactions such as $p+p=p+n+\pi^{+}$or $p+p=d+\pi^{+}$(ref. 3) and $p+\pi^{-}=n+\pi^{0}$ (ref. 4 ).

The isotopic spin formalism has been widely used from the early days for computations concerning few-body nuclear systems ; here it introduces nothing new but it makes the calculations look neater. If, however, we do not simply regard isotopic spin as a formal means of distinguishing neutron from proton but are prepared to link the formalism with a specific assumption concerning nuclear forces, we obtain novel results that are of considerable importance for the classification of many-body nuclear systems and for understanding certain apparently capricious aspects of nuclear reactions; it is not clear how certain of these results could be obtained outside the isotopic spin formalism except perhaps in a very cumbersome fashion. The assumption that we must make is that the specifically nuclear forces (that is, after allowing for the Coulomb and electromagnetic interactions) are independent of charge; $n-n, p-p$ and $n-p$ forces are equal in corresponding states. The total isotopic spin $T$ of the system, formed from the isotopic spins of the individual nucleons according to the usual rules for the addition of angular momenta ${ }^{1,5}$, then becomes a good, or almost good, quantum number, and its conservation in certain circumstances together with the selection rules governing its behaviour in others become matters of great physical consequence; the behaviour of the component along the $z$-axis, $T_{z}=\frac{1}{2}(N-Z)$, is generally trivial. Although we are unable, in any simple physical sense, to say what isotopic spin is, it is clear that the $2 T+1$ members of the isotopic spin multiplet represented by the $2 T+1$ values of $T_{z}$ are simply all the different chemical elements that we may make from a given nuclear wavefunction by turning neutron into proton and vice versa without change of that wave function before a halt is called by the Pauli exclusion principle. States that appear only in the self-conjugate $\left(T_{z}=0\right)$ nucleus are then of $T=0$; those that appear also in the neighbouring isobaric nuclei of $T_{z}= \pm 1$ are of $T=1$ and so on. The self-conjugate nucleus has the most states; those of $T=0$ cannot be transferred to the neighbouring isobars by conversion of 